\title{
Scientific and technical aspects of grouting of marginal rocks of mine workings
}

\author{
Serhii Musiienko ${ }^{1, *}$, Tetiana Palamarchuk ${ }^{1}$, Liliia Prokhorets $^{1}$, and Volodymyr Kurinnyi ${ }^{2}$ \\ ${ }^{1}$ Institute of Geotechnical Mechanics named by N. Poljakov of National Academy of Sciences of \\ Ukraine, 49005, Dnipro, Simferopolska Str., 2a, Ukraine \\ ${ }^{2}$ Dnipro University of Technology, 49005, Dnipro, Dmytra Yavornytskoho Ave., 19, Ukraine
}

\begin{abstract}
The goal of the paper is to justify ways to achieve maximum radius of extent of grouting mortar in a rock massif and to maximize filling of cavities and cracks with minimal openings. Filling of cavities and cracks directly influences a "massif - roadway - safety structure" system. Some scientific and technical aspects of grouting and injecting inorganic binders into marginal rocks are considered. Advantages of usage of triple plunger pumps in injecting units are determined. The influence of pulsation on a condition and process of grouting mortar extension is justified. It is established that under equal operating conditions, pulsations created by a triple plunger pump reduce mortar viscosity by $15 \%$, and a radius of extent of mortar based on grouting cements is increased by an average of $12 \%$, and with usage of very finely dispersed substances - up to $20 \%$. Suggested recommendations significantly improve the technology of grouting of marginal rocks and concrete structures.
\end{abstract}

\section{Introduction}

Accidental collapse of a rock massif causes a displacement of rocks on a contour of workings, leading to deformation of supports and loss of operating space. Management of massif condition is controlled influence on natural occurrence of geomechanical processes around a working via technological and technical methods and means in modern mining terminology. The goal of management is to provide pre-determined parameters of displacement of rocks.

A group of methods of influence on a stress-strain state of marginal rocks can be distinguished among a variety of other methods. A mechanism of realization of these methods is based on interaction of rocks and binding materials. There are cementing, chemical, and electrochemical methods of treatment of rocks depending on a character of used binding material. This paper considers only the methods that use cement or cementbased materials: grouting, injection, and shotcreting. Concrete usage is recommended in mining and underground construction in certain conditions as a particularly rational and economical method of support of marginal rocks. Combinations of supports create a geocomposite structure with unique properties in a rock massif. Such combinations introduce new and tougher requirements to elements of structures and require further

*Corresponding author: mspdop@i.ua 
research and development.

The following grouting technologies are prioritized: surface shotcreting, grouting of area behind supports, and injection during marginal construction or repair works. New methods of grouting and shotcreting are being realized along with widely used methods of concrete placing behind a sheathing. Combinations of various types of supports are of particular interest. Combinations of supports are created inside a rock massif. Distinctive features of host rocks of Ukrainian mines are variable strength, stratification, and fracturing. Thus, creating a monolithic structure of host rocks is one of the main problems of supports of mine workings. Geocomposite systems of supports are used more often due to an increase of depth and worsening of mining and geological conditions of extraction. Grouting and injection of binding materials are used in such systems. Also, problems of achieving a required radius of extent of grouting mortar and maximum filling of cracks with minimal openings. Filling of cavities and cracks directly influences a condition of a "massif - roadway - safety structure" system.

Piston or plunger pumps are most commonly used for pumping of mortar [1]. Cycle of operation of a plunger pump is shown in Figure 1.

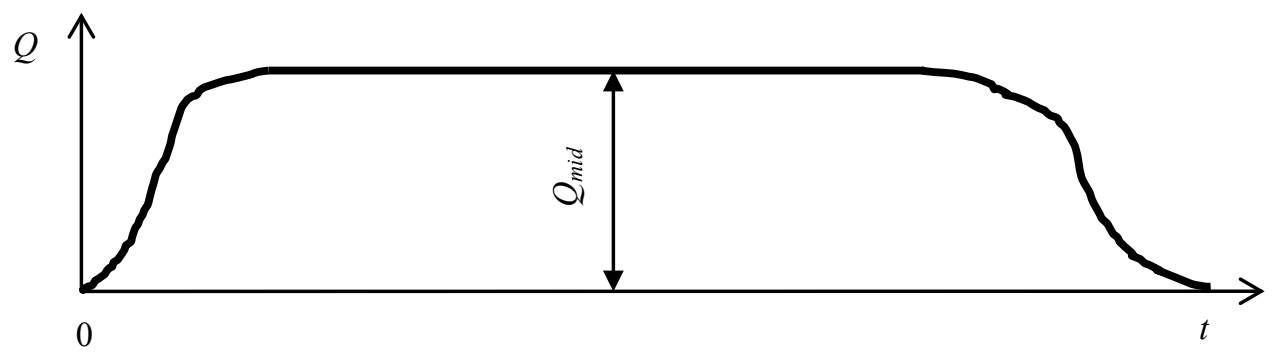

Fig. 1. Dependency of average pump output $Q_{\text {mid }}$ on pumping cycle duration $t$.

Plunger pumps are quite convenient when filling substantial cavities, which require pumping of large amounts of mortar at large flow rate, and transporting mortar over long distances. However, mortar flow rate through a well decreases when grouting a fractured massif and a pump pumping cycle becomes comparable to a period of binder sedimentation. This leads to water separation and plugging of cracks. Pump output regulation and a circulatory scheme of pump operation do not solve the issue, since the circulation occurs within the injection well.

The goal of the paper is to justify methods of achieving maximum radius of extent of grouting mortar in a massif and maximum filling of cavities and cracks with minimal openings. Filling of cavities and cracks directly influences a condition of a "massif roadway - safety structure" system.

\section{Methods}

Grouting of marginal rocks has specific features. Reliability of created geocomposite structures depends on these features. Application of regular grouting methods and serial equipment reduces the effect of grouting. A change of radius of extent of grouting mortar on constructive features of a pump is discovered using an experimental unit, which is developed by Institute of Geotechnical Mechanics named by N. Poljakov of National Academy of Sciences of Ukraine (IGTM NAS of Ukraine). A value of mortar mobility is determined by submersion depth of a standard cone in mortar [2]. Flow table test is performed with AzNII cone (Kr-1 by Technical conditions 25-04-52 75). Plastic viscosity is determined by a rotational viscometer VSN-3. Sedimentation stability of grouting mortar is 
estimated by a coefficient of water separation using a cylinder for cement paste separation test. The coefficient is determined by a value of relation of separated water volume and initial volume of grouting mortar $\left(250 \mathrm{~cm}^{3}\right)$ using the formula (1).

$$
B=\left(V_{1}-V_{2}\right) / V_{1} 100, \%
$$

where $B$ is coefficient of water separation, $\% ; V_{1}$ is initial volume of grouting mortar, $\mathrm{cm}^{3}$; $V_{2}$ - volume of sedimented grouting mortar, $\mathrm{cm}^{3}$.

A method and tool for estimation of strength of rocks and elements of geocomposite structures are applied in order to estimate a change of radius of extent of grouting mortar using a method of impact impulse [3]. A method of drilling control wells is additionally applied at some areas. A constructive analysis of techniques, equipment types in use, and influence of pumping cycles on grouting mortar mobility is performed. Ways of improving the equipment and technologies are suggested based on the analysis results. Experimental verification of equipment and technologies is performed.

Methods of analysis and generalization of practical results, hydrodynamics, physical chemistry (the experimental method), nondestructive testing methods of rock massifs and concrete structures are used during solving the formulated problems. Propriety of the results is confirmed by correctness of theoretical assumptions, which are based on fundamental principles of theory and practice, by utilizing proven methods of measuring, and natural experiments.

\section{Results and discussion}

Operation of standing supports of mines is based mainly on a principle when loading occurs after deformation of a marginal layer of rocks. It means that the initial triaxial stress state is transformed into uniaxial or biaxial one as a result of displacement and loosening of rocks. This is achieved through fulfilling consecutive intermediate stages, during which various processes of stress redistribution occur. Rock contour stability and standing support functionality improves when filling the area behind supports is applied [4]. The end result depends both on time and method of filling the cavities. It is expedient in many cases to use grouting with inexpensive liquid binders. In general, this additional measure gives the following static effects:

- a support starts operating and prevents spreading stress-strain state changes and destruction of rocks deep into the massif;

- a combined operating resistance of a steel arch support, of a concrete layer in the area behind the support, and of cemented marginal rocks is provided;

- a load on support frames is evenly distributed, carrying capacity of the material is better used, and loads that correspond to the structure are created;

- stability of support arches to longitudinal bending increases.

Maximum result is achieved when the area behind supports is fully filled with binder material and marginal rocks are cemented. Important parameters during grouting are a mortar radius of extent and a radius of filling of cavities and cracks with small openings. These parameters depend on a type and rheological characteristics of mortar.

It should be noted that, according to a classical Prandtl's boundary layer theory, mortar movement along a crack length is accompanied by energy dissipation. It happens in a zone of contact with walls, where large stress gradients occur along a normal to the flow. It is known, that a static layer of sedimented particles is formed on a lower crack wall. A flow of compacted core of increased concentration occurs at a certain distance over the static layer of sedimented particles, limited by a crack roof. 
A scheme of filling a crack with cement material (Fig. 2) is suggested based on the results of experimental and theoretical studies carried out by PJSC "KuzNIIshakhtostroy" and KuzSTU [5]. The mortar moves from the injection well. Three zones of mortar flow from the well are distinguished according to this scheme.

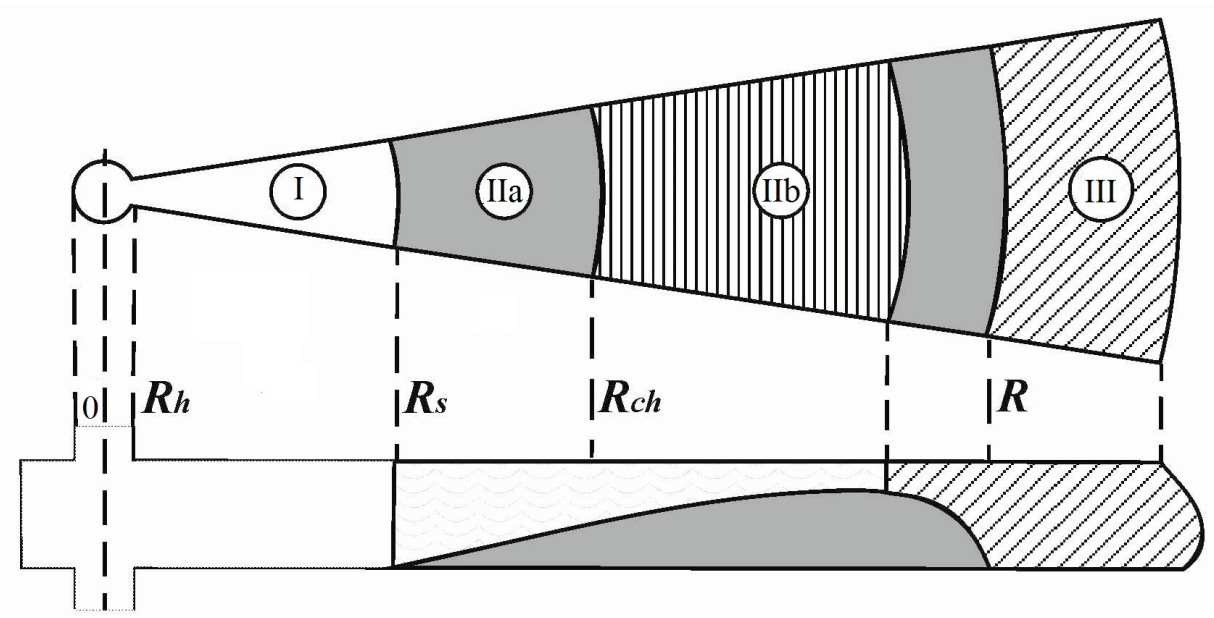

Fig. 2. Scheme of flat radial filtration of mortar in one crack: $R_{h}$ is hole (well) radius, $R_{s}$ is radius of sedimentation zone beginning, $R_{c h}$ is radius of channel formation beginning, $R$ is maximum possible radius of mortar extension.

Non-sedimentation mortar movement at a velocity, which exceeds the critical nonsedimentation velocity is observed in zone I.

A stable sediment is formed in zone II due to sedimentation of cement particles as a result of flow velocity decrease. A flow with a constant velocity and a constant crosssection area is established during sedimentation over a sedimented solid phase. Axisymmetric mortar flow transforms into a plane flow through individual channels at a certain distance from the well in zone $\mathrm{II}_{\mathrm{b}}$ over time.

The distance, at which the mortar starts flowing through separate channels in zone II can be roughly determined based on a ratio provided that the sediment surface area and the upper crack wall area are equal [5].

$$
2\left(R_{c h}^{2}-R_{s}^{2}\right)=\frac{4 \delta}{R_{s}} R_{s}\left(R_{c h}-R_{s}\right),
$$

where $\delta$ is average crack opening.

A flow of a filtered liquid phase of mortar is observed in zone III.

It should be noted that large cracks with openings of more than $1 \mathrm{~cm}$ are filled, and smaller cracks are not filled during a stage of grouting of area behind supports. This is especially true for cracks with openings of less than $0.1 \mathrm{~cm}$. Cracks with openings of at least $(0.1-0.2) 10^{-3} \mathrm{~m}$ can be cemented. Penetration of mortar into a crack depends on a number of factors, the main of which are: crack opening, size of solid particles, flow pressure, flow character, and viscosity.

Grouting of marginal rocks is performed in order to add another element to a geocomposite safety structure. Also, the problem of achieving both the required radius of extent of grouting mortar and the maximum filling of cavities and cracks with minimal openings is set. This problem can be solved by selecting a dispersity of grouting mortar components, or by selecting a process of injecting mortar into a massif, or by pseudofluidization and sedimentation slowdown. 
It is known that if an additional impulse (excess pressure $\Delta p$ and therefore excess density $\Delta \rho$ ) is quickly created in a small area in an immobile or uniformly moving fluid, then these disturbances propagate over time with a certain velocity, consequently setting the particles of medium in motion on the way of propagation. Propagation velocity does not depend on a specific type of disturbance, unless relative changes $\Delta p / p<<1$ and $\Delta \rho / \rho<<1$ ( $p$ and $\rho$ are equilibrium values of pressure and density of the medium). It is important to note that a form of such small disturbances in a propagation process does not change [6].

Pulsations of fluid pressure create flow instability, which causes turbulence in the flow. All these turbulent flows have common properties. Three-dimensional non-stationary character, presence of both large (coherent) and very small chaotic structures in the flow. Chaotic fluctuations (pulsations) of main hydrodynamic variables - pressure, temperature, and velocity take place in the turbulent flow.

Pulsations (primarily velocity pulsations) provide additional transfer of impulse, energy, etc. There is a significant change in all main characteristics of the flow. Stationary motion of fluids (laminar motion) loses stability and becomes turbulent at values of Reynolds number (Re) that exceed a certain critical value. Critical values of Re are different for different flows, but not very large. Therefore, the vast majority of real flows in nature and technology are turbulent. There is a strong mixing of a fluid in a turbulent flow mode. The mixing is determined by a value of an average velocity.

The flow mode is selected in each case based on available possibilities. Cementing is performed under flow modes, the area of existence of which is determined by the following Re values:

$0<\operatorname{Re}<64$ - "plugging" mode;

$64<\operatorname{Re}<700$ - transitional mode from "plugging" to structural;

$700<\operatorname{Re}<1600$ - structural mode;

$1600<\operatorname{Re}<2300$ - transitional mode from structural to turbulent;

$\operatorname{Re}>2300$ - turbulent mode.

The best result is achieved during a turbulent flow mode with values of a generalized criterion $\operatorname{Re}>2300$ [7].

Fluid particles have very complex trajectories during turbulent motion as a result of intense vortex formation, and local velocities are not constant even in a case when the output is kept constant in time. Thus, steady motion does not exist in a turbulent flow.

Sedimentation influences grouting mortar mobility. Sedimentation occurs if a directed movement of particles prevails over the chaotic movement under the action of gravity or centrifugal force. Sedimentation rate depends on mass, size and shape of particles, viscosity and density of medium, and acceleration that occurs when the upper-mentioned forces act on particles. Sedimentation is often accompanied by enlargement of sedimentation particles of mortar in disperse systems due to coagulation or coalescence [8].

Vibrational energy during mortar pulsation is expended on disturbing or completely destroying structural bonds of a cement gel and lowering viscosity. Mechanical (dynamic) actions of various intensity are required for pseudo-fluidization of cement gel within the specified boundaries. The smaller the distance between particles $X$, the stronger the coagulation structure, the higher should be the frequency of forced vibrations. In this case, their amplitude can be arbitrarily small, since the absolute value of deformations that cause destruction of structural bonds and mutual displacements of particles is comparable with a radius of action of Van der Waals forces. The effect is achieved at a vibration frequency of more than $15 \mathrm{~Hz}$ with an amplitude of $(0.2-0.4) 10^{-3} \mathrm{~m}$, and the most intensive mortar movement occurs at a frequency of $40-200 \mathrm{~Hz}$ [9]. Bonds between particles are restored and mortar viscosity increases after the vibration stops. Therefore, it is necessary to apply influence to mortar throughout the transportation.

In natural conditions, pulsations can be created by using injecting equipment with a 
triple plunger pump, which is a type of a displacement pump. The constructive feature of a plunger pump is its operating body - the plunger. The plunger task is to move along the cylinder axis. The plunger movement is performed by an electric drive, which rotates a crankshaft. Plunger pumps and triple plunger pumps in particular, have operating characteristics that are somewhat different from piston pumps. Figure 3 shows a diagram of operation of a triple plunger pump.

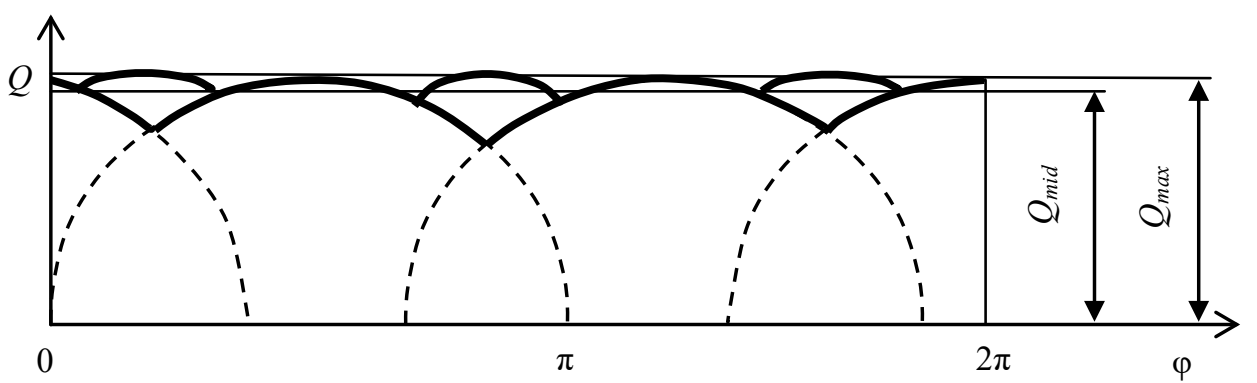

Fig. 3. Dependency of average $Q_{\text {mid }}$ and maximum $Q_{\max }$ pump output on current crank rotation angle $\varphi$.

Pump cranks are arranged at an angle of $120^{\circ}$ to one another. Therefore, the total output of all three cylinders is characterized by a graph obtained as a result of addition of three sinusoids offset by $120^{\circ}$ relatively to one another. Thus, the current pump output is formed by simultaneous outputs of several plungers that are located in a pumping cavity. Therefore, the flow $Q_{\max }$ is discrete, pulsating. A degree of output irregularity is an important indicator of a pump, which represents a ratio of maximum output to an average one for one crank rotation. The flow is discrete, pulsating. The number of output maximums per rotor rotation is equal to the number of cylinders for single-row pumps with an even number of cylinders. However, for pumps with an odd number of cylinders it is double the number of cylinders. An uneven output creates pulsations of fluid pressure in a pump and throughout the pumping system, which have a character of sound vibrations.

As shown above, an additional impulse can be created using triple plunger pumps. The required characteristics of the impulse are achieved by selecting plunger diameters and rotational velocity of a pump crankshaft.

Mortar with a high water-cement ratio are used for grouting of marginal rocks. This type of mortar can be fluidized by mechanical actions in a wide range of amplitudes and frequencies. In this case, a transition to turbulent flow prevents sedimentation and mortar coagulation. A viscosity decrease of grouting mortar achieved in this way increases a radius of extent of mortar in the supported marginal rocks and, accordingly, a strength of rocks after mortar hardening.

Considering the points above, a concrete placing machine with a triple plunger pump is developed and experiments are carried out on grouting of marginal rocks of permanent mine workings and concrete structures. A comparative analysis of parameters of application of piston pumps and triple plunger pumps is performed. A comparison of parameters of pumps is presented in Table 1. The data is obtained during injecting mortar based on grouting cements.

The experimental data allows drawing the following conclusions. Mortar dynamic viscosity at pumping pipeline outlet during pumping by a piston pump increases by $4.5 \%$ with equal values at the pump inlet. When pumped by a triple plunger pump it decreases by $14 \%$. Spreadability of mortar at pumping pipeline outlet during pumping by a piston pump does not change. When pumped with a triple plunger pump, the spreadability increases by $23 \%$. Values of coefficient of water separation at pumping pipeline outlet practically does 
not change. This is explained by the fact that after the pulsation stops, the bonds between particles are restored, and the properties of mortar obtain values closer to the original ones.

Table 1. Comparison of operating parameters of pumps.

\begin{tabular}{|c|c|c|}
\hline Parameter & $\begin{array}{l}\text { Piston } \\
\text { pump }\end{array}$ & $\begin{array}{c}\text { Triple plunger } \\
\text { pump }\end{array}$ \\
\hline Piston diameter, $\mathrm{mm}$ & 120 & 40 \\
\hline Piston stroke, $\mathrm{mm}$ & 1200 & 120 \\
\hline $\begin{array}{l}\text { Outlet pressure, } \mathrm{MPa} \text { : } \\
\text { average } \\
\text { maximum }\end{array}$ & $\begin{array}{l}1.0 \\
1.0\end{array}$ & $\begin{array}{l}1.0 \\
1.6\end{array}$ \\
\hline Water / cement ratio & 0.8 & 0.8 \\
\hline Grouting mortar density, $10^{4} \mathrm{~N} / \mathrm{m}^{3}$ & 1.51 & 1.51 \\
\hline Pumping pipeline length, $\mathrm{m}$ & 40 & 40 \\
\hline Pumping pipeline diameter, $\mathrm{mm}$ & 38 & 38 \\
\hline Mortar density at pump inlet, $\mathrm{g} / \mathrm{cm}^{3}$ & 1.92 & 1.92 \\
\hline Mortar viscosity at pump inlet, $\mathrm{Pa} \cdot \mathrm{s} \cdot 10^{-3}$ & 1.77 & 1.77 \\
\hline Mortar viscosity at pumping pipeline outlet, $\mathrm{Pa} \cdot \mathrm{s} \cdot 10^{-3}$ & 1.85 & 1.51 \\
\hline Spreadability at pump inlet, $\mathrm{mm}$ & 260 & 260 \\
\hline Spreadability at pumping pipeline outlet, $\mathrm{mm}$ & 260 & 320 \\
\hline Coefficient of water separation at pump inlet, $\%$ & 2.4 & 2.4 \\
\hline $\begin{array}{l}\text { Coefficient of water separation at pumping pipeline } \\
\text { outlet, } \%\end{array}$ & 2.6 & 2.4 \\
\hline
\end{tabular}

Rheological parameters decrease during transportation of cement mixture by a piston pump as shown in Table 1. Sedimentation manifests at the pipeline outlet. Rheological parameters increase during transportation of cement mixture by a triple plunger pump. Considering the points above, it can be concluded that the pulsation in a pipeline transitions the flow into a turbulent mode with a corresponding pseudo-fluidization of mortar.

Natural experiments are conducted at the mines of "Pavlohradcoal" and "Luhanskvuhillia" companies, and on concrete structures of the Dnieper Hydroelectric Station. Operating control of condition of geocomposite structures is performed when conducting experimental studies on their creation. Nondestructive testing methods are preferred for quick estimation of current strength of hardening material directly at the place of material usage. A domestic standard DSTU B V.2.7-220:2009 is actual in Ukraine. This standard regulates methodology and tools for nondestructive testing of concrete. A technique and a tool for estimating strength of rocks and elements of geocomposite structures using the impact impulse method is used in this paper, which can be used in underground conditions. A close correlation between two data arrays - values of impact impulse duration and uniaxial compression strength is established [3]. A method of drilling control wells is additionally applied at some areas.

It is established that pulsations created by a triple plunger pump reduce mortar viscosity by $15 \%$, and a radius of extent of mortar based on grouting cements is increased by an average of $12 \%$, and when using very finely dispersed substances - up to $20 \%$ under equal operating conditions. Grouting mortar viscosity at pipeline outlet is decreased by $8.2 \%$.

Problems of injection supports are always about the durability and strength of structures being supported, as well as in ecological and sanitary safety of injection mortar used. This is more important for uranium mines. Usage of very fine substances allows combining the efficiency of injection technologies and elimination of ecological and sanitary problems. It is possible because finely dispersed substances are mineral binders with long-term preservation of properties, provide high strength and durability of supports, and are sanitary 
safe materials. The market currently offers a variety of special grouting mortars based on inorganic binders for various conditions, including very finely dispersed substances. A scale of their application depends on a compromise between technical possibilities of fine grinding and pricing policies of dealers.

The research results can be used for supports of workings in fractured rocks, strengthening safety pillars, pit walls, etc., and also for strengthening deformable monolithic concrete and reinforced concrete structures. Such supports can be used both independently and with other types of supports: frame, anchor, frame-anchor, concrete, reinforced concrete. The selection of such combinations depends on specific mining and geological conditions of a mine working and its purpose.

The results are incorporated into regulatory documentation [10]. Approbation of the results in various mining and geological conditions of mines during grouting and injection of marginal rocks [11] and cementation of massive concrete structures [12] confirmed the correctness of results. Increasing the radius of mortar extension improves the monolithic character of host rocks and thereby the reliability of supports of mine workings and concrete structures due to the greater filling of small cracks. Implementation of the results in the industry does not require additional funding or other resources.

\section{Conclusions}

It is established that geomechanical parameters of host rocks of uranium mines of Ukraine require usage of special methods of supports of permanent and development workings, including the creation of geocomposite safety structures.

One of the elements of creation of safety structures is achieving a monolithic structure of host rocks using methods of grouting or injection of mortar based on inorganic binders. Grouting mortar with usage of very finely dispersed substances is the most efficient.

It is expedient to use very finely dispersed substances in a form of water suspension for creating a monolithic structure of marginal rocks. The usage of very finely dispersed substances is not technologically different from injection of resins and other polymeric compositions. The difference is in the fact that very finely dispersed substances correspond to the host rocks in their physical and chemical properties because of being a mineral binder.

It is possible to increase the degree of filling of cracks in marginal rocks by changing the condition of injected grouting mortar. Pulsations of fluid pressure create flow instability, which causes turbulence in the flow. Fluid particles have very complex trajectories during turbulent motion as a result of an intense vortex formation. Practically speaking, an additional impulse can be created by using triple plunger pumps. The required characteristics of the impulse are achieved by selecting diameters of plungers and a frequency of pump crankshaft rotation.

It is established that pulsations created by a triple plunger pump reduce mortar viscosity by $15 \%$, and a radius of extent of mortar based on grouting cements increases by an average of $12 \%$, and when using very finely dispersed substances - up to $20 \%$ under equal operating conditions.

Increasing the radius of extent of mortar improves the monolithic character of host rocks and thereby the reliability of supports of mine workings and concrete structures due to the greater filling of small cracks. The methodology and the means for estimating the strength of rocks and elements of geocomposite structures by the impact impulse method can be used in underground conditions.

The results are part of the program "Promoting the development of priority research areas" (KPKVK 6541230) of state funding for the National Academy of Sciences of Ukraine. 


\section{References}

1. Khaiutin, Yu.G. (1991). Monolitnyi beton. Moskva: Stroyizdat

2. Popov, L.N. (1986). Laboratornyi control stroitelnykh materialov i izdelii. Spravochnik. Moskva: Stroyizdat

3. Prokhorets, L. On the informativeness of the shock pulse method for controlling the geocomposite constructions strength. E3S Web of Conferences, International Conference Essays of Mining Science and Practice, 109 (2019). https://doi.org/ $10.1051 / \mathrm{e} 3$ sconf $/ 201910900072$

4. Musiienko, S.P. (2007). Primenenie specialnykh sposobov stroitelstva pri vozvedenii vysokonagruzhennykh kombinirovannykh okhrannykh system. Geotekhnichna Mekhanika [Geo-Technical Mechanics], 68, 285-292

5. Khiamialiainen, V.A., Uglianitsa, A.V. (2000). Tsementatsiya sloistykh porod. Kemerovo: Kuzbas. Gos. Univ

6. Aleshkevich, V.A., Dedenko, L.G., Karavayev, V.A. Continuum mechanics. Available at: http://www.astronet.ru/db/msg/1173645/lect3-4.html

7. Khiamialiainen, V.A., Mayorov A.YE. (2012). Osobennosti techeniya cementacionnykh rastvorov pri uprochnenii treshhinovatykh gornykh porod. Gornyy informatsionnoanaliticheskiy byulleten, 8, 104-109

8. Concrete physics fundamentals. Pseudo-liquefaction (thixotropy) of cement gel. Available at: https://msd.com.ua/osnovy-fiziki-betona/psevdorazzhizhenie-tiksotropiyacementnogo-gelya/

9. Chistiakov, A.N., Hayrutdinov, M.M., Artiuhov, E.V. (2009). Vliyanie razlichnykh sposobov aktivacii na phiziko-mekhanicheskie svoystva zakladki. Gornyy informatsionno-analiticheskiy byulleten, 3, 232-246

10. Bulat, A. F. et al. (2011). Tekhnologicheskiy reglament diagnostiki I vosstanovleniya zaglublennykh I podzemnykh sooruzheniy poverkhnostnogo kompleksa shakht na osnove sozdaniya geokompozitnykh konstruktsiy. Dnipropetrovsk: Monolit

11. Musiienko, S.P. (2012). Primenenie elementov tekhnologii sozdaniya geokompozitnykh konstrukcii v usloviyakh remonta promyshlennykh obyektov. Geotekhnichna Mekhanika [Geo-Technical Mechanics], 97, 115-124

12. Osadchiy, S.D., Gerasimovich, N.M., Musiienko, S.P. (2007). Analiz i podkhody k razrabotke tekhnologicheskikh resheniy rekonstruktsii i remonta gidrotekhnicheskikh sooruzheniy. Gidrotekhnicheskoye stroitelstvo, 8, 7-11 